\title{
T1-Weighted Dynamic Contrast-Enhanced MRI as a Noninvasive Biomarker of Epidermal Growth Factor Receptor vIII Status
}

\author{
(D). Arevalo-Perez, (D)A.A. Thomas, (D)T. Kaley, (D). Lyo, (D)K.K. Peck, (D)A.I. Holodny, (D).K. Mellinghoff, \\ (D)W. Shi, Z. Zhang, and (DR.J. Young
}

\begin{abstract}
BACKGROUND AND PURPOSE: Epidermal growth factor receptor variant III is a common mutation in glioblastoma, found in approximately $25 \%$ of tumors. Epidermal growth factor receptor variant III may accelerate angiogenesis in malignant gliomas. We correlated T7-weighted dynamic contrast-enhanced MR imaging perfusion parameters with epidermal growth factor receptor variant III status.

MATERIALS AND METHODS: Eighty-two consecutive patients with glioblastoma and known epidermal growth factor receptor variant III status who had dynamic contrast-enhanced MR imaging before surgery were evaluated. Volumes of interest were drawn around the entire enhancing tumor on contrast Tl-weighted images and then were transferred onto coregistered dynamic contrast-enhanced MR imaging perfusion maps. Histogram analysis with normalization was performed to determine the relative mean, 75 th percentile, and 90 th percentile values for plasma volume and contrast transfer coefficient. A Wilcoxon rank sum test was applied to assess the relationship between baseline perfusion parameters and positive epidermal growth factor receptor variant III status. The receiver operating characteristic method was used to select the cutoffs of the dynamic contrast-enhanced MR imaging perfusion parameters.
\end{abstract}

RESULTS: Increased relative plasma volume and increased relative contrast transfer coefficient parameters were both significantly associated with positive epidermal growth factor receptor variant III status. For epidermal growth factor receptor variant III-positive tumors, relative plasma volume mean was 9.3 and relative contrast transfer coefficient mean was 6.5; for epidermal growth factor receptor variant III-negative tumors, relative plasma volume mean was 3.6 and relative contrast transfer coefficient mean was 3.7 (relative plasma volume mean, $P<.001$, and relative contrast transfer coefficient mean, $P=.008)$. The predictive powers of relative plasma volume histogram metrics outperformed those of the relative contrast transfer coefficient histogram metrics $(P<=.004)$.

CONCLUSIONS: Dynamic contrast-enhanced MR imaging shows greater perfusion and leakiness in epidermal growth factor receptor variant III-positive glioblastomas than in epidermal growth factor receptor variant III-negative glioblastomas, consistent with the known effect of epidermal growth factor receptor variant III on angiogenesis. Quantitative evaluation of dynamic contrast-enhanced MR imaging may be useful as a noninvasive tool for correlating epidermal growth factor receptor variant III expression and related tumor neoangiogenesis. This potential may have implications for monitoring response to epidermal growth factor receptor variant III-targeted therapies.

ABBREVIATIONS: DCE $=$ dynamic contrast-enhanced; EGFR $=$ epidermal growth factor receptor; $K^{\text {trans }}=$ contrast transfer coefficient; $K^{\text {trans }}=$ relative $K^{\text {trans; }}$; $\mathrm{ROC}=$ receiver operating characteristic; $\mathrm{rVP}=$ relative plasma volume; $75 \%$ tile $=75$ th percentile; $90 \%$ tile $=90$ th percentile; $\mathrm{VP}=$ plasma volume

G lioblastoma is the most common and aggressive primary brain tumor. A highly malignant tumor, it is associated with a dismal median survival of only 14 months with standard ra-

Received March 6, 2015; accepted after revision April 30

From the Departments of Radiology (J.A.-P., J.L., A.I.H., R.J.Y.), Neurology (A.A.T., T.K., I.K.M.), Medical Physics (K.K.P.), and Epidemiology and Biostatistics (W.S., Z.Z.), and the Brain Tumor Center (T.K., J.L., A.I.H., R.J.Y.), Memorial Sloan Kettering Cancer Center, New York, New York.

Drs Julio Arevalo-Perez and Alissa A. Thomas contributed equally to the work as coauthors.

Julio Arevalo-Perez was supported by a grant from the Spanish foundation "Fundación Alfonso Martín Escudero." The research of Weiji Shi and Zhigang Zhang was partly supported by the National Institutes of Health Core Grant P30 CA008748. diochemotherapy. ${ }^{1}$ Glioblastoma is characterized by histologic heterogeneity with areas of active cellular proliferation and mitoses admixed with areas of necrosis. Large-scale genetic sequencing has revealed "driver" mutations in several common pathways that contribute to glioblastoma growth. ${ }^{2}$ Among these, overactivation of the epidermal growth factor receptor (EGFR) membrane ty-

Paper previously presented as a scientific poster at: Annual Meeting of the American Society of Neuroradiology and the Foundation of the ASNR Symposium, April 25-30, 2015; Chicago, Illinois.

Please address correspondence to Robert J. Young, MD, Department of Radiology, Memorial Sloan Kettering Cancer Center, 1275 York Ave, NY, New York 10065; e-mail: youngr@mskcc.org

- Indicates open access to non-subscribers at www.ajnr.org

http://dx.doi.org/10.3174/ajnr.A4484 
rosine kinase receptor pathway contributes to rapid aberrant cell proliferation and drives tumor growth and development. ${ }^{3-5}$ EGFR variant III (EGFRvIII) is the most common EGFR mutation in glioblastoma, occurring in $25 \%-35 \%$ of cases. ${ }^{6}$ EGFRvIII is characterized by deletion of exons $2-7$ in the extracellular domain, rendering the receptor constitutively active. EGFRvIII status is determined either through exon sequencing or fluorescence in situ hybridization on tumor specimens.

The growing interest in EGFRvIII-specific therapy and other EGFR-targeted treatments for glioblastoma demands a better understanding of the correlation between molecular changes in tumors and neuroimaging features. Prior studies have demonstrated a correlation of $\mathrm{T} 2{ }^{\star}$ dynamic susceptibility contrast MR imaging perfusion with EGFR amplification and EGFRvIII mutations. ${ }^{5,7}$ The role of T1-weighted dynamic contrast-enhanced (DCE)-MR imaging in distinguishing molecular subpopulations of glioblastoma, however, has not been well-established, to our knowledge. DCE-MR imaging offers several technical advantages over DSC-MR imaging, including improved characterization of tumor vascularity through quantification of plasma volume (VP) and improved characterization of tumor leakiness through calculation of the contrast transfer coefficient $\left(K^{\text {trans }}\right){ }^{8-10}$ The purpose of this study was to examine the relationship between T1-weighted DCE-MR imaging perfusion parameters and EGFRvIII status in patients with newly diagnosed glioblastoma. We hypothesized that patients with glioblastomas positive for EGFRvIII would demonstrate increased perfusion and leakiness at DCE-MR imaging compared with patients with EGFRvIII-negative glioblastomas.

\section{MATERIALS AND METHODS}

\section{Protocol Approval and Informed Consent}

The local institutional review board approved this retrospective study, which was compliant with the Health Insurance Portability and Accountability Act regulations. The requirement to obtain patient informed consent was waived.

\section{Subjects}

A hospital data base was queried from March 2011 through March 2014 to identify all patients meeting the following inclusion criteria: 1) pathologically confirmed glioblastoma diagnosis after biopsy or resection, 2) EGFRvIII status obtained from the biopsy or the resection specimen, and 3) baseline DCE-MR imaging perfusion scan with matching postcontrast axial T1-weighted images before surgery. EGFRvIII status was determined by reverse transcriptase polymerase chain reaction amplification of the corresponding exons followed by a single base extension at the site of the mutation. The single base extension product was detected by tandem mass spectrometry on a MassArray Spectrometer (Sequenom, San Diego, California) and reported in a binary manner as either positive or negative.

\section{MR Imaging Protocol}

MR imaging sequences were acquired with a $1.5 \mathrm{~T}$ or 3T MR imaging scanner (Signa Excite, HDx, and Discovery 750; GE Healthcare, Milwaukee, Wisconsin) and a standard 8-channel head coil. Gadopentetate dimeglumine (Magnevist; Bayer HealthCare
Pharmaceuticals, Wayne, New Jersey) was power-injected via an intravenous catheter (18-21 ga) at doses standardized by patient body weight $(0.2 \mathrm{~mL} / \mathrm{kg}$ body weight, maximum $20 \mathrm{~mL})$ at $2-3$ $\mathrm{mL} / \mathrm{s}$. DCE-MR imaging of the brain was acquired as part of a standard clinical protocol with a 3D T1-weighted echo-spoiled gradient-echo sequence (TR, 4-5 ms; TE, 1-2 ms; section thickness, $5 \mathrm{~mm}$; flip angle, $25^{\circ}$; FOV , $24 \mathrm{~cm}$; matrix, $256 \times 256$; temporal resolution, 5-6 seconds. Ten phases were acquired preinjection followed by another 30 phases during the dynamic injection of intravenous contrast and then a $40-\mathrm{mL}$ saline flush. Matching contrast T1-weighted (TR/TE, 600/8 ms; thickness, 5 $\mathrm{mm}$ ) spin-echo images were obtained.

\section{Imaging Analysis}

DCE perfusion MR imaging raw data and T1-weighted images were transferred to an off-line workstation and processed by using commercially available software (nordicICE; (NordicNeuroLab, Bergen, Norway) by a trained radiologist who was blinded to the EGFRvIII status. Preprocessing steps included noise adjustments and semiautomated selection of the arterial input function. These steps allowed the operator to optimize the signal-to-noise ratio and the arterial input function by selecting an appropriate artery to characterize the input function curve and the concentration-time curve. ${ }^{11}$ The arterial input function was calculated individually for every patient. Appropriate curves demonstrating an optimal relationship between the arterial input function and the concentration-time curve were selected. On the basis of the 2-compartment pharmacokinetic model proposed by Tofts et al, ${ }^{12}$ the perfusion analysis method was applied to determine pharmacokinetic parameters, and the results were displayed as parametric maps. Volumes of interest were drawn on axial planes on contrast T1weighted images, excluding intralesional macrovessels, to not contaminate the measurements. VOIs were transferred to coregistered parametric maps to obtain the pharmacokinetic parameters VP and $K^{\text {trans }}$. Parameters were then normalized by using the ratio of tumor to normal white matter by placing ROIs in normal white matter of the contralateral hemisphere in a healthy-appearing area of brain parenchyma. The values were then binned into histograms, and the relative mean VP $\left(\mathrm{rVP}_{\text {mean }}\right)$, 90th percentile $\mathrm{VP}\left(\mathrm{rVP}_{90 \% \text { tile }}\right)$, and 75 th percentile $\left(\mathrm{rVP}_{75 \% \text { tile }}\right)$ ratios were recorded, along with the relative mean $K^{\text {trans }}\left(\mathrm{r} K_{\text {mean }}^{\text {trans }}\right)$, 90th percentile $K^{\text {trans }}\left(r K^{\text {trans }}{ }_{90 \% \text { tile }}\right)$, and 75 th percentile $K^{\text {trans }}\left(\mathrm{r} K^{\text {trans }}{ }_{75 \% \text { tile }}\right)$ ratios.

\section{Statistical Analysis}

Univariate analysis by using the Wilcoxon rank sum test was performed to examine the correlations between the $\mathrm{rVP}$ and $\mathrm{r} \mathrm{K}^{\text {trans }}$ histogram parameters and EGFRvIII status. The cutoffs of the DCE-MR imaging perfusion parameters were selected by using the receiver operating characteristic (ROC) method. The areas under the ROC curves of the perfusion parameters were compared by using the Delong test. The statistical analysis was performed with the software SAS, Version 9.2 (SAS Institute, Cary, North Carolina) and R package ROCR and pROC (Version 3.1.2; $\mathrm{R}$ statistical computing software; http://www.r-project.org/). The significance level was set to $P=.05$.

AJNR Am J Neuroradiol 36:2256-61 Dec 2015 www.ajnr.org 


\section{RESULTS}

\section{Patient Characteristics}

Eighty-two consecutive treatment-naïve patients with glioblastoma were included in the study. Twenty-four (29.3\%) patients had positive EGFRvIII status, while 58 (70.7\%) had negative EGFRvIII status. The median age was 66.7 years (range, $38-87$ ) years; there were 21 women $(25.6 \%)$ and 61 men $(74.4 \%)$.

\section{DCE-MR Imaging}

As summarized in the Table, increased VP and $K^{\text {trans }}$ were asso-

\section{Analysis of the relationship between baseline perfusion} parameters and EGFRvIII mutation status

\begin{tabular}{|c|c|c|c|c|}
\hline \multirow[b]{2}{*}{$\begin{array}{l}\text { Perfusion } \\
\text { Parameter }^{\mathrm{a}}\end{array}$} & \multicolumn{2}{|c|}{$\begin{array}{l}\text { EGFRvIII Status } \\
\text { (Median, Range) }\end{array}$} & \multirow[b]{2}{*}{$P$ Value } & \multirow[b]{2}{*}{ AUC } \\
\hline & $\begin{array}{l}\text { Negative } \\
(n=58)\end{array}$ & $\begin{array}{l}\text { Positive } \\
(n=24)\end{array}$ & & \\
\hline$r V P_{\text {mean }}$ & $3.6(1.5-18.1)$ & $9.3(2.9-29.3)$ & $<.001$ & 0.818 \\
\hline $\mathrm{rVP}_{90 \% \text { tile }}$ & $5.1(1.6-19.1)$ & $10.7(4.1-30.2)$ & $<.001$ & 0.833 \\
\hline $\mathrm{rVP}_{75 \% \text { tile }}$ & $4.2(1.6-18.4)$ & $9.2(3.5-28.1)$ & $<.001$ & 0.821 \\
\hline$r K^{\text {trans }}$ mean & $3.7(1.1-20.3)$ & $6.5(1.7-22.4)$ & .008 & 0.688 \\
\hline$r K^{\text {trans }} 90 \%$ tile & $4.8(1.5-22.6)$ & $7.6(2.1-31.8)$ & .02 & 0.669 \\
\hline$r K^{\text {trans }} 75 \%$ tile & $4.2(1.4-19.7)$ & $6.8(1.9-24.7)$ & .007 & 0.692 \\
\hline
\end{tabular}

Note:-AUC indicates area under the curve in the ROC analysis.

${ }^{a}$ All values are relative ratios normalized to tumor/contralateral normal tissue. ciated with positive EGFRvIII status for all histogram metrics. $\mathrm{rVP}_{\text {mean }}, \mathrm{rVP}_{90 \% \text { tile, }}$, and $\mathrm{rVP}_{75 \% \text { tile }}$ were better predictors than $\mathrm{r} K_{\text {mean }}^{\text {trans }}, \mathrm{r}^{\text {trans }}{ }_{90 \% \text { tile, }}$, and $\mathrm{r} K^{\text {trans }}{ }_{75 \% \text { tile, }}$ with $P$ values $\leq .004$. A representative case is shown in Fig 1 . The areas under the ROC curves for the VP metrics were 0.818-0.833, while those for the $K^{\text {trans }}$ metrics were $0.669-0.692$. With ROC analysis, a threshold value for $\mathrm{VP}_{90 \% \text { tile }}>9.50$ yielded a specificity of $89.7 \%$ and a sensitivity of $62.5 \%$ for predicting positive EGFRvIII status (Fig 2).

\section{DISCUSSION}

We demonstrated that perfusion and leakiness, as determined by $\mathrm{rVP}$ and $\mathrm{r} K^{\text {trans }}$ histogram parameters, respectively, were greater in EGFRvIII-positive glioblastomas than in EGFRvIII-negative glioblastomas. These results suggest that DCE-MR imaging parameters may be useful imaging biomarkers to follow in patients with EGFRvIII-positive tumors or other tumors with abnormal pretreatment parameters. We postulate that this radiogenomic characterization may be particularly relevant in patients undergoing active targeted, mutation-specific treatment, in which changes in perfusion and leakiness could be used to repetitively and noninvasively evaluate treatment efficacy in lieu of surgery.

Alteration of EGFR is among the frequent oncogene muta-

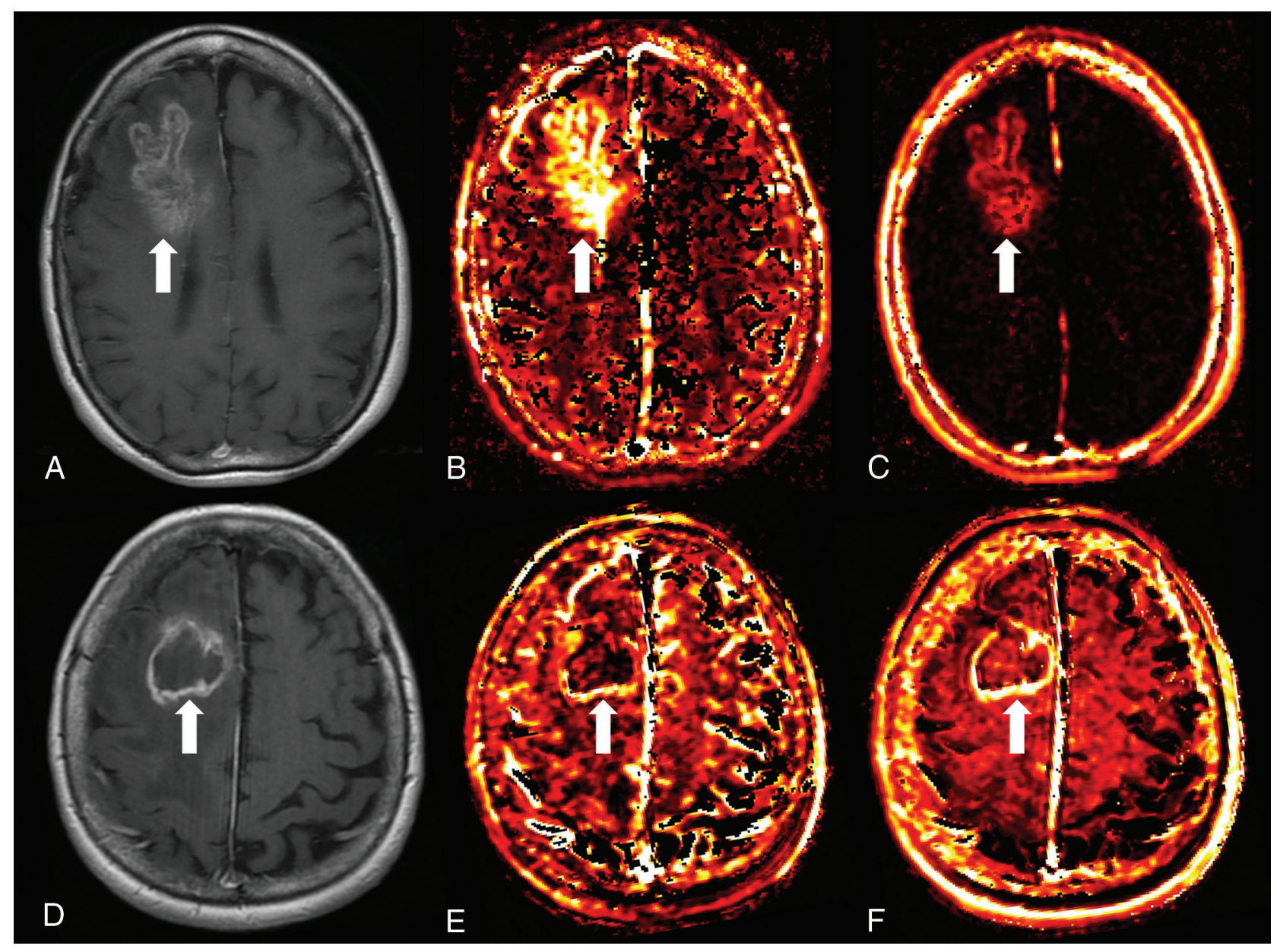

FIG 1. Representative DCE-MR images and parametric maps from a patient with EGFRvIII-positive glioblastoma. Axial contrast T1-weighted (A) image demonstrates a large heterogeneously enhancing tumor in the right frontal lobe. Corresponding VP $(B)$ and $K^{\text {trans }}(C)$ maps reveal increased perfusion and increased leakiness, respectively, as indicated by the arrows. Matching images in a non-EGFRvIll glioblastoma in the right frontal lobe $(D-F)$ show little increase in VP or $K^{\text {trans }}$. 

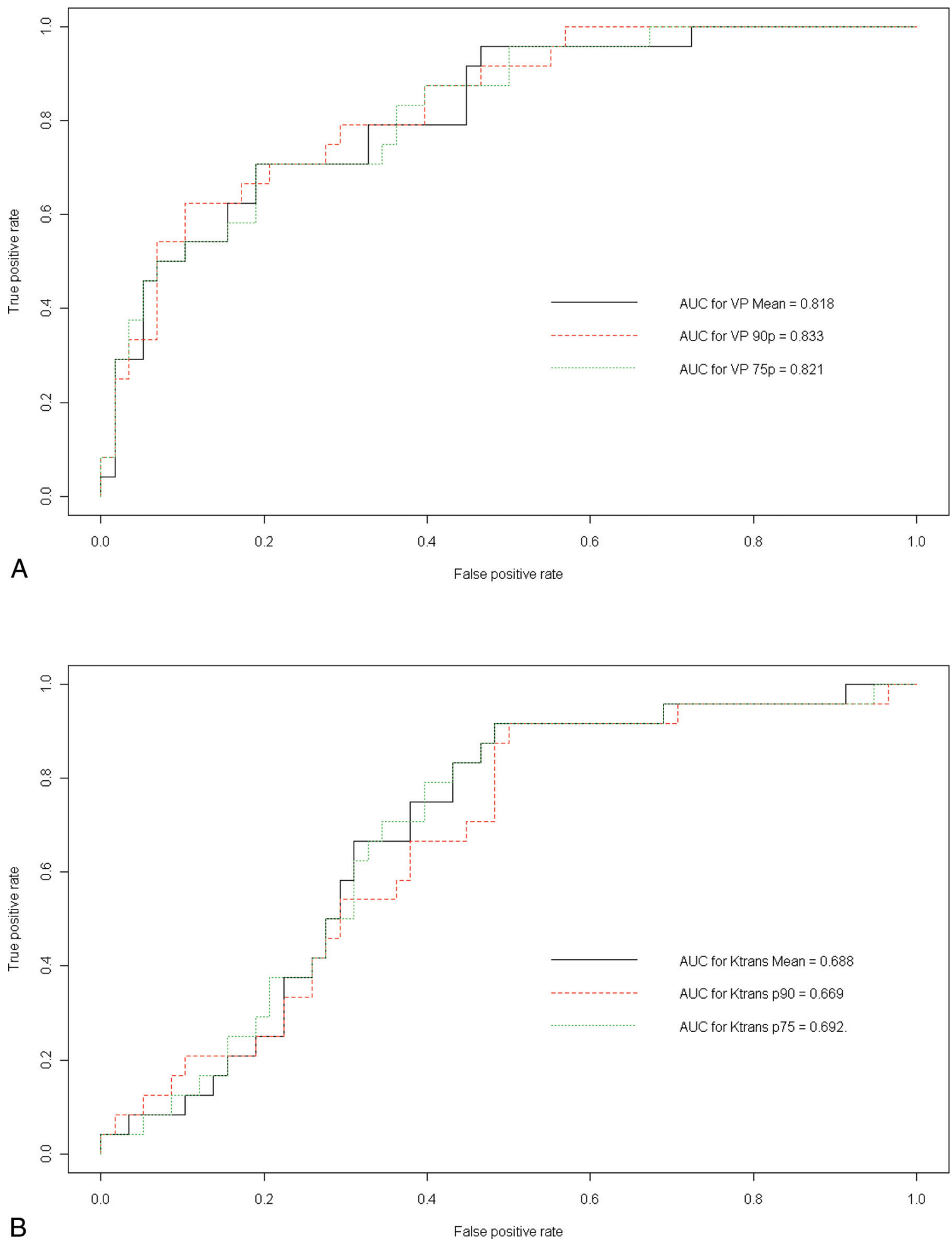

FIG 2. Discrimination power of baseline VP $(A)$ and $K^{\text {trans }}(B)$ perfusion parameters for EGFR status (positive versus negative).

tions in primary glioblastomas. ${ }^{13-15}$ In addition to promoting cellular growth and proliferation, EGFRvIII accelerates tumor angiogenesis and induction of proangiogenic factors, including vascular endothelial growth factor, interleukin 18 , and angiopoietin-like 4 in the extracellular signal-regulated kinase and $c-M y c$ pathways, to confer a more heterogeneous and aggressive phenotype. ${ }^{16-19}$ These increases in angiogenic activity in patients with
EGFRvIII may manifest at DCE-MR imaging as increased VP, which is a measure of the tumor blood plasma volume per unit volume of tissue, and as increased $K^{\text {trans }}$, the volume transfer constant between the blood plasma and the extravascular extracellular space.

Due to its unique protein sequence and tumor-specific expression, EGFRvIII is an attractive target for drug therapy. Several 
small molecular tyrosine kinase inhibitors with affinity for the $E G F R$ receptor are available on the market and under development in clinical trials. ${ }^{20}$ A glioblastoma vaccine based on a unique EGFRvIII peptide sequence is currently under investigation in a phase III clinical trial. ${ }^{21}$ Effective implementation of these novel targeted therapies will require parallel development of targeted imaging technologies such as DCE-MR imaging, also specific for particular mutations.

Perfusion on MR imaging has been shown to correlate with glioma grade, prognosis, and response to treatment. ${ }^{22-26}$ Perfusion parameters may be useful as imaging markers of vascular attenuation and angiogenesis in gliomas. ${ }^{2,27}$ Increased relative tumor blood volume shown by DSC perfusion MR imaging has been associated with EGFR amplification and EGFRvIII mutation. ${ }^{5,7}$ The $2^{*}$ technique may render DSC-MR imaging inadequate, however, in areas with leakage of contrast through an abnormal blood-brain barrier or in areas with strong susceptibility artifacts due to blood, vessel, bone, and air interfaces such as those near the skull base. ${ }^{10-28}$ DCE-MR imaging offers several potential advantages, ${ }^{8}$ the most important of which is the more accurate quantification of perfusion and leakiness through greater spatial resolution, steady-state imaging, and advanced compartmental modeling. ${ }^{8-10}$ We also advocate the use of histogram analysis after whole-tumor VOI evaluation, which should yield measurements that are more objective and reproducible and less user-dependent than those obtained with the usual ROI-based methods. ${ }^{7-29}$

There are a few potential limitations to the present study. First, this retrospective study included patients with glioblastoma with EGFRvIII status determined by reverse transcriptase polymerase chain reaction. Whole exome sequencing was not available for these patients, so we did not account for other mutations or amplifications in EGFR that may also correlate with changes in DCE-MR imaging. Our observed frequency of mutant EGFRvIII, however, was consistent with the frequency reported in the literature. ${ }^{5-30}$ Second, given the retrospective nature of this study, an inherent limitation is the absence of stereotactic localization in cases of biopsy or subtotal resection. Tissue sampling error may confound the assessment of EGFRvIII status (ie, undersampling of less metabolically active areas in heterogeneous tumors may lead to erroneous correlations, eg, false-negatives). Third, the VOIs were manually drawn around the enhancing tumor and then transferred onto the coregistered DCE-MR imaging perfusion maps, which may have introduced bias and variability. For example, subjectivity would be expected in terms of exclusion of vessels within the lesions. To account for this subjectivity, we inspected the VOIs in each case and adjusted them as necessary to match the enhancing tumor. To reduce operator variability, we chose to have all of these steps performed by a single experienced user trained in the use of the DCE-MR imaging software. Other groups have advocated semiautomated segmentation and coregistration; however, the validity and interinstitutional reproducibility of results obtained with their proprietary tools, which were developed in-house, remain unproven. ${ }^{31}$ We believe that the expertise of a trained user of commercially available DCE-MR imaging software best matches the expertise available at most institutions and broadens the applicability of our results. A dual-rater or multiple-rater consensus approach could have also been an optimal way to assess uniform ROI placement.

\section{CONCLUSIONS}

We found that EGFRvIII-positive glioblastomas demonstrate greater vascular leakiness and perfusion than do EGFRvIII-negative glioblastomas. Quantitative evaluation of DCE-MR imaging may be useful as a noninvasive tool for correlating EGFRvIII expression and related tumor neoangiogenesis. This may have implications for monitoring response to EGFRvIIItargeted therapies.

\section{ACKNOWLEDGMENTS}

The authors are grateful for the expert editorial advice provided by Ada Muellner, MS.

Disclosures: Julio Arevalo-Perez-OTHER RELATIONSHIPS: Research fellow the Memorial Sloan Kettering Cancer Center supported by a grant from the Spanish foundation "Fundación Alfonso Martín Escudero." Andrei I. Holodny-UNRELATED: Other: fMRI Consulting, LLC, Comments: a purely educational endeavor. Robert J. Young-UNRELATED: Payment for Development of Educational Presentations: Novocure; Travel/Accommodations/Meeting Expenses Unrelated to Activities Listed: Agios.

\section{REFERENCES}

1. Stupp R, Mason WP, van den Bent MJ, et al; European Organisation for Research and Treatment of Cancer Brain Tumor and Radiotherapy Groups, National Cancer Institute of Canada Clinical Trials Group. Radiotherapy plus concomitant and adjuvant temozolomide for glioblastoma. $N$ Engl J Med 2005;352:987-96 CrossRef Medline

2. Jain R, Poisson L, Narang J, et al. Correlation of perfusion parameters with genes related to angiogenesis regulation in glioblastoma: $a$ feasibility study. AJNR Am J Neuroradiol 2012;33:1343-48 CrossRef Medline

3. Huang PH, Xu AM, White FM. Oncogenic EGFR signaling networks in glioma. Sci Signal 2009;2:re6 CrossRef Medline

4. Mellinghoff IK, Wang MY, Vivanco I, et al. Molecular determinants of the response of glioblastomas to EGFR kinase inhibitors. $N$ Engl J Med 2005;353:2012-24 CrossRef Medline

5. Gupta A, Young RJ, Shah AD, et al. Pretreatment dynamic susceptibility contrast MRI perfusion in glioblastoma: prediction of EGFR gene amplification. Clin Neuroradiol 2015;25:143-50 CrossRef Medline

6. Kastenhuber ER, Huse JT, Berman SH, et al. Quantitative assessment of intragenic receptor tyrosine kinase deletions in primary glioblastomas: their prevalence and molecular correlates. Acta Neuropathol 2014;127:747-59 CrossRef Medline

7. Tykocinski ES, Grant RA, Kapoor GS, et al. Use of magnetic perfusion-weighted imaging to determine epidermal growth factor receptor variant III expression in glioblastoma. Neuro Oncol 2012;14: 613-23 CrossRef Medline

8. Essig M, Shiroishi MS, Nguyen TB, et al. Perfusion MRI: the five most frequently asked technical questions. AJR Am J Roentgenol 2013;200:24-34 CrossRef Medline

9. Cao Y, Sundgren PC, Tsien CI, et al. Physiologic and metabolic magnetic resonance imaging in gliomas. J Clin Oncol 2006;24:1228-35 CrossRef Medline

10. Shin KE, Ahn KJ, Choi HS, et al. DCE and DSC MR perfusion imaging in the differentiation of recurrent tumour from treatment-related changes in patients with glioma. Clin Radiol 2014;69:e264-72 CrossRef Medline

11. Jung SC, Yeom JA, Kim JH, et al. Glioma: application of histogram analysis of pharmacokinetic parameters from T1-weighted 
dynamic contrast-enhanced MR imaging to tumor grading. AJNR Am J Neuroradiol 2014;35:1103-10 CrossRef Medline

12. Tofts PS, Brix G, Buckley DL, et al. Estimating kinetic parameters from dynamic contrast-enhanced T(1)-weighted MRI of a diffusable tracer: standardized quantities and symbols. J Magn Reson Imaging 1999;10:223-32 CrossRef Medline

13. Brennan CW, Verhaak RG, McKenna A, et al. The somatic genomic landscape of glioblastoma. Cell 2013;155:462-77 CrossRef Medline

14. Cancer Genome Atlas Research Network. Comprehensive genomic characterization defines human glioblastoma genes and core pathways. Nature 2008;455:1061-68 CrossRef Medline

15. Heimberger AB, Hlatky R, Suki D, et al. Prognostic effect of epidermal growth factor receptor and EGFRvIII in glioblastoma multiforme patients. Clin Cancer Res 2005;11:1462-66 CrossRef Medline

16. Hirata A, Ogawa S, Kometani T, et al. ZD1839 (Iressa) induces antiangiogenic effects through inhibition of epidermal growth factor receptor tyrosine kinase. Cancer Res 2002;62:2554-60 Medline

17. Ali MM, Janic B, Babajani-Feremi A, et al. Changes in vascular permeability and expression of different angiogenic factors following anti-angiogenic treatment in rat glioma. PLoS One 2010;5:e8727 CrossRef Medline

18. Katanasaka Y, Kodera Y, Kitamura Y, et al. Epidermal growth factor receptor variant type III markedly accelerates angiogenesis and tumor growth via inducing c-myc mediated angiopoietin-like 4 expression in malignant glioma. Mol Cancer 2013;12:31 CrossRef Medline

19. Inda MM, Bonavia R, Mukasa A, et al. Tumor heterogeneity is an active process maintained by a mutant EGFR-induced cytokine circuit in glioblastoma. Genes Dev 2010;24:1731-45 CrossRef Medline

20. Thomas AA, Brennan CW, DeAngelis LM, et al. Emerging therapies for glioblastoma. JAMA Neurol 2014;71:1437-44 CrossRef Medline

21. Xu LW, Chow $\mathrm{KK}, \operatorname{Lim} \mathrm{M}$, et al. Current vaccine trials in glioblastoma: a review. J Immunol Res 2014;2014:796856 CrossRef Medline

22. Mills SJ, Patankar TA, Haroon HA, et al. Do cerebral blood volume and contrast transfer coefficient predict prognosis in human glioma? AJNR Am J Neuroradiol 2006;27:853-58 Medline

23. Law M, Oh S, Babb JS, et al. Low-grade gliomas: dynamic susceptibility-weighted contrast-enhanced perfusion MR imagingprediction of patient clinical response. Radiology 2006;238: 658-67 CrossRef Medline

24. Aronen HJ, Gazit IE, Louis DN, et al. Cerebral blood volume maps of gliomas: comparison with tumor grade and histologic findings. $R a-$ diology 1994;191:41-51 CrossRef Medline

25. Ellika SK, Jain R, Patel SC, et al. Role of perfusion CT in glioma grading and comparison with conventional MR imaging features. AJNR Am J Neuroradiol 2007;28:1981-87 CrossRef Medline

26. Wetzel SG, Cha S, Johnson G, et al. Relative cerebral blood volume measurements in intracranial mass lesions: interobserver and intraobserver reproducibility study. Radiology 2002;224:797-803 CrossRef Medline

27. Jain R, Gutierrez J, Narang J, et al. In vivo correlation of tumor blood volume and permeability with histologic and molecular angiogenic markers in gliomas. AJNR Am J Neuroradiol 2011;32:388-94 CrossRef Medline

28. Fatterpekar GM, Galheigo D, Narayana A, et al. Treatment-related change versus tumor recurrence in high-grade gliomas: a diagnostic conundrum - use of dynamic susceptibility contrast-enhanced (DSC) perfusion MRI. AJR Am J Roentgenol 2012;198:19-26 CrossRef Medline

29. Young R, Babb J, Law M, et al. Comparison of region-of-interest analysis with three different histogram analysis methods in the determination of perfusion metrics in patients with brain gliomas. $J$ Magn Reson Imaging 2007;26:1053-63 CrossRef Medline

30. Gan HK, Kaye AH, Luwor RB. The EGFRvIII variant in glioblastoma multiforme. J Clin Neurosci 2009;16:748-54 CrossRef Medline

31. Jung SC, Choi SH, Yeom JA, et al. Cerebral blood volume analysis in glioblastomas using dynamic susceptibility contrast-enhanced perfusion MRI: a comparison of manual and semiautomatic segmentation methods. PLoS One 2013;8:e69323 CrossRef Medline 